\title{
MODERN TRENDS OF FORMATION OF VEGETATION UNDER DIFFERENT PHYSICAL-GEOGRAPHIC CONDITIONS IN SOUTH- WESTERN TRANS-BAIKAL
}

\author{
Victor Voronin ${ }^{1}$, Alexander Sizykh ${ }^{1 *}$ \\ ${ }^{1 *}$ Siberian Institute of Plants Physiology and Biochemistry of RAS SB, \\ 664033 Irkutsk, 132 Lermontova str., Russia; \\ *Corresponding author Alexander Sizykh e-mail: alexander.sizykh@gmail.com;
}

Received April 2021; Accepted May 2021; Published June 2021;

DOI: $\underline{\text { https://doi.org/10.31407/ijees11.336 }}$

\begin{abstract}
The dynamics of vegetation formation during last decades on the background of the climate variability in continental-regional scale reflects modern trends of phytocoenoses development under different physical-geographic conditions in the Baikal Region. Due to this fact, timely corrections in determination of the vector of successional changes in belt-zonal differentiation of the vegetation cover become very actual at modern stage of trend in the phytocoenoses development. Vegetation formation in different environments must be as well considered within the whole biome. In this case, phytocoenoses at environments contact (transition) reflect the most rapidly in time all occurred and occurring changes in their structural-dynamic organization, therefore they are best models in the system of the monitoring of vegetation development at vast territories.
\end{abstract}

Key words: vegetation, successions, phytocoenoses of environments contact, monitoring, South-Western TransBaikal. 